\title{
Envolvimento materno e desempenho acadêmi- co: comparando crianças residindo com a mãe e com ambos os pais
}

\author{
Envolvimento materno e desempenho acadêmico \\ Carolina Severino Lopes da Costa \\ Fabiana Cia \\ Elizabeth Joan Barham
}

\begin{abstract}
Resumo
Este estudo objetivou comparar o envolvimento materno de crianças que vivem com a mãe e com ambos os pais e o desempenho acadêmico de crianças que vivem nesses dois contextos e relacionar a freqüência de envolvimento materno com o desempenho acadêmico das crianças. Participaram 30 crianças com idades entre 9 e $\mathrm{II}$ anos, alunos de $3^{\mathrm{a}}$ e $4^{\mathrm{a}}$ séries, metade vivendo em famílias monoparentais e metade com ambos os pais. Para avaliar o desempenho escolar das crianças, utilizou-se o Teste de Desempenho Escolar (TDE). Para caracterizar o envolvimento materno, usou-se ० Questionário da Qualidade da Interação Familiar na Visão dos Filhos. Os resultados mostraram que houve algumas diferenças significativas no envolvimento materno nos dois grupos. Além disso, o envolvimento materno no grupo monoparental apresentou uma relação muito maior com o desempenho escolar de seus filhos do que no grupo biparental.
\end{abstract}

Palavras-chave: famílias monoparentais; família; desempenho acadêmico.

\section{Maternal involvement and academic performance: comparing children living with their mother and with both parents}

\begin{abstract}
This study aimed to compare maternal involvement among children living with their mother or with both parents and the academic performance of children in these two family contexts and correlate the frequency of the mother's involvement with their child's academic performance. The 30 children who participated in this study ranged in age from 9 to 1 I years, studying in the third or fourth grade, with half living in single-parent families and half living with both parents. The Academic Achievement Test (AAT) was used to evaluate the children's academic performance. The Questionnaire on the Quality of Family Interactions - Child Version captured maternal involvement. Results showed that there were several significant differences between the two children's groups, in terms of their mothers' involvement. In addition, maternal involvement in the single parent group showed a much stronger relationship with the children's academic performance than in the two parent groups.
\end{abstract}

Keywords: singles parents; family; academic achievement.

\section{Envolvimiento materno y desempeño académico: comparando niños viviendo con la madre y con los dos padres.}

\begin{abstract}
Resumen
Este estudio tuvo como objetivo: comparar el envolvimiento materno de niños que viven con la madre y con los dos padres; comparar el desempeño académico de niños que viven en esos dos contextos y relacionar la frecuencia de envolvimiento materno con el desempeño académico de los niños. Participaron 30 niños con edades entre 9 y $1 \mathrm{I}$ años, alumnos de $3^{\circ}$ y $4^{\circ}$ grado, siendo que mitad vivía en familias mono parentales y mitad con los dos padres. Para evaluar el desempeño escolar de los niños se utilizó el Teste de Desempenho Escolar (TDE). Para caracterizar el envolvimiento materno se utilizó el Questionário da Qualidade da Interação Familiar na Visão dos Filhos. Los resultados mostraron algunas diferencias significativas em el envolvimiento materno em los dos grupos. Además de eso, el envolvimiento materno en el grupo mono parental presentó una relación mucho mayor con el desempeño escolar de sus hijos en comparación al grupo bi-parental.
\end{abstract}

Palabras clave: familias mono parentales; família; desempeño académico. 
A família, como instituição social, tem passado por muitas mudanças em sua estrutura. Ferreira (2005) aponta que as mudanças ocorridas no último século caminham para uma redução do número de membros da família. O modelo que predominava nas sociedades rurais, no início do século $X X$, denominado a Família estendida, compreendia pai, mãe, filhos, tios, avós, primos etc.

Entretanto, com a urbanização e o aparecimento de meios cada vez mais eficazes e socialmente aceitáveis no controle de natalidade, houve redução no tamanho da família, passando para uma nova estrutura predominante, denominada Família nuclear (pai-mãefilhos). Esta estrutura estava mais bem adaptada aos custos de vida na cidade e ao novo papel social e profissional da mulher que deixou de ser exclusivamente uma dona de casa, tornando-se, ao lado do marido, provedora do lar (Brandth \& Kvande, 2002; Dantas, Jablonski \& Féres-Carneiro, 2004).

Apesar do conceito da família nuclear "intacta" permanecer como a estrutura ideal na cultura ocidental, a existência de outras estruturas aumenta a cada dia (Kauffman, 200I). Dados do censo do IBGE-2000 (conforme citado por Ferreira, 2005) destacam questões importantes para a compreensão da vida familiar atual, em relação ao censo anterior: a família de tipo nuclear diminuiu de $58,4 \%$ para $55 \%$; o número de mulheres sem marido (viúvas, mães solteiras, divorciadas) aumentou de $15,1 \%$ para $17,1 \%$ e o número de pessoas vivendo sozinhas aumentou de 7,3\% para $8,6 \%$. Conclui-se que a prevalência do modelo da família nuclear está diminuindo, enquanto outros modelos de vivência têm emergido (Dessen \& Silva, 2004).

Um fator que mantêm a visão da família nuclear como um modelo ideal diz respeito à comprovada importância do envolvimento dos pais com os filhos para o desenvolvimento sócio-emocional e acadêmico das crianças (Applyard, Egeland, Dulmen \& Sroufe, 2005; Dunn, 2004; Hill \& Taylor, 2004). O progresso no aprendizado escolar, por exemplo, está associado à supervisão e à organização das rotinas no lar, a oportunidades de interação com os pais e à oferta de recursos no ambiente físico (Marturano, 2004). Contudo, existem muitas crianças que não gozam da oportunida- de de serem educadas, diariamente, por ambos os pais.

Quando os dois pais não vivem no mesmo domicílio com seus filhos, quase sempre há uma freqüência baixa de contato com o pai não-residente. Sabe-se que uma proporção substancial de crianças tem sido criada ou educada dentro de famílias monoparentais, usualmente resultante de divórcio, mas também provenientes de nascimentos fora do casamento, viuvez precoce, em função de um local de trabalho distante por parte do pai, entre outros motivos (Dessen \& Silva, 2004; Kauffman, 200I).

Em geral, o divórcio é considerado de forma negativa, pois é visto como um evento traumático, tanto para os pais como também para as crianças. No início, muitas crianças manifestam alguns distúrbios emocionais, tipicamente envolvendo uma combinação de raiva, ansiedade, depressão, dependência e nãosubmissão. O período de adaptação ao divórcio é de aproximadamente três anos, embora existam crianças que se ajustem rapidamente e seguem suas vidas sem apresentarem problemas emocionais e/ou comportamentais (Kauffman, 200I).

Apesar do período de adaptação poder ser difícil, deve-se ressaltar que a separação dos pais pode ter aspectos positivos para todos os membros da família, principalmente quando a criança vivenciava situações de violência física e verbal, ou quando um dos pais tem comportamento anti-sociais, o que poderia trazer maiores intercorrências para o seu desenvolvimento se os pais permanecessem unidos (Guille, 2004; Jaffee, Moffitt, Caspi \& Taylor, 2003).

A forma como as crianças se ajustam ao divórcio depende de várias circunstâncias associadas à dissolução familiar, incluindo a idade das crianças quando o divórcio ocorreu, nível de conflito familiar antes e após o divórcio, nível de afeiçoamento da criança ao cônjuge possuidor da custódia, características do cuidador que tem a custódia, comportamento do progenitor visitante, situação econômica do responsável pelas crianças, suporte de outros membros da família e características cognitivas e afetivas das crianças (Zigler \& Finn-Stevenson, 1997).

Não é possível predizer com precisão a ocorrência de desordens afetivas e comportamentais infantis decorrentes do divórcio, porém muitas crianças e 
adolescentes que têm pais separados apresentam desempenho escolar mais baixo e menor confiança em suas habilidades acadêmicas, quando comparadas com crianças de famílias intactas (Kauffman, 200I).

Além da intensificação desses fatores de risco que acompanham o divórcio, é preocupante os impactos desta separação dos pais sobre a freqüência e a qualidade da interação entre o principal cuidador (normalmente a mãe) e as crianças. Por um lado, o contexto monoparental pode reduzir o tempo que - cuidador principal tem para interagir com seus filhos, uma vez que este se encontra sozinho para executar muitas funções (trabalhar fora, realizar tarefas domésticas, dar atenção aos filhos). Por outro lado, pode ser que esta pessoa passe a contar com a maior colaboração de seus filhos do que em famílias bi-parentais, gerando uma interdependência familiar maior e elevado senso de responsabilidade entre estas crianças, que pode estreitar e fortalecer esta relação.

Soma-se o fato que a ausência ou baixo envolvimento do pai, em si, constitui um fator de risco adicional ao desenvolvimento das crianças, pois várias pesquisas demonstraram que o envolvimento do pai afeta a dedicação dos seus filhos aos estudos, com impactos no seu desempenho acadêmico (Flouri \& Buchanan, 2003; Gutman, Sameroff \& Cole, 2003; Lamb, 1997).

Em uma pesquisa envolvendo crianças em idade escolar, Cia, D'Affonseca e Barham (2004) verificaram a relação entre a qualidade do relacionamento com o pai (na visão do pai e da criança) e o desempenho acadêmico das crianças. Participaram deste estudo 58 pais (homens) e seus filhos da quinta e sexta série, de classes socioeconômicas baixa, que viviam com ambos os pais biológicos. Os resultados demonstraram que a maior freqüência de comunicação entre pai e filho, bem como, a de participação do pai nas atividades escolares, culturais e de lazer do filho estava positivamente correlacionada com melhor desempenho da criança em leitura, escrita e na pontuação total do Teste de Desempenho Escolar.

Considerando que a ausência paterna se configura como fator de risco para o desenvolvimento infantil, pesquisas que possam averiguar a freqüência do envolvimento de mães sozinhas com seus filhos, comparadas com mães em contextos bi-parentais, podem contribuir na identificação de fatores de proteção, que reduzem o risco para o desenvolvimento infantil.

Além disso, podem fornecer dados importantes que subsidiam o planejamento de intervenções para auxiliar as famílias monoparentais a organizarem e distribuírem seu tempo de modo a maximizar oportunidades de interação e o desenvolvimento acadêmico dos filhos. Sendo assim, os objetivos deste estudo são comparar o envolvimento materno de crianças que vivem com a mãe ou com ambos os pais e o desempenho acadêmico de crianças que vivem nesses dois ambientes familiares e relacionar a freqüência de envolvimento materno com o desempenho acadêmico das crianças.

\section{Método}

\section{Participantes}

Participaram deste estudo 30 crianças, com idades variando entre 9 e II anos (média de idade de 9,6 anos), sendo 13 do sexo feminino e 17 do sexo masculino. Exatamente metade estava na $3^{\text {a }}$ série e a outra metade na $4^{\mathrm{a}}$ série do Ensino Fundamental, assim como, metade vivia com ambos os pais e metade apenas com a mãe. Todas as crianças eram de classe sócio-econômica baixa.

\section{Local}

A pesquisa foi realizada em uma instituição que atende crianças carentes, disponibilizando aulas de reforço, atividades esportivas e recreativas, em período oposto ao das aulas. Essa instituição está localizada em uma cidade de médio porte do interior do estado de São Paulo.

\section{Materiais e Instrumentos}

Teste de Desempenho Escolar - TDE (Stein, 1994). O TDE é um instrumento com propriedades psicométricas adequadas para avaliar capacidades fundamentais para o desempenho escolar. Pode ser empregado para avaliar crianças desde a la à $6^{a}$ séries do 
Ensino Fundamental, composto por três subtestes: escrita, envolvendo a escrita do nome próprio e de 34 palavras isoladas, apresentadas sob a forma de ditado; aritmética, que requer a solução oral de três problemas e cálculos de 35 operações aritméticas, por escrito e leitura, requerendo o conhecimento de 70 palavras, isoladas do contexto.

Questionário da Qualidade da Interação Familiar na Visão dos Filhos (Cia e cols., 2004). Este instrumento é composto por várias escalas, tipo Likert, e contemplam uma diversidade de indicadores de envolvimento positivo dos pais com os filhos. Neste estudo, foram utilizadas três escalas, com a pontuação de freqüência para os itens, variando entre I, 'nunca' a 5, 'sempre', que foram adaptadas para utilização nessa pesquisa, sendo elas:

I- Escala de freqüência de interações iniciadas pela mãe, para com seu filho, contendo 16 itens $(\alpha=0,8 \mathrm{I})$;

2- Escala de freqüência de interações iniciadas pelo filho, para com sua mãe, contendo 15 itens $(\alpha=0,67)$;

3- Escala de freqüência de participação das mães nas atividades escolares, culturais e de lazer dos filhos, contendo 32 itens $(\alpha=0,85)$.

\section{Procedimento de coleta de dados}

Para obter a autorização dos responsáveis (neste estudo, sempre as mães) e para solicitar a participação das crianças, foi agendada, primeiramente, uma reunião em que foram apresentados os objetivos do estudo, a forma de participação das crianças e, para as interessadas, solicitou-se a assinatura no Termo de Consentimento Livre e Esclarecido. Em seguida, foram agendados horários para aplicar o TDE e para preenchimento do questionário pelas crianças. Apesar de o questionário ser um instrumento preenchido pelo participante, todos os itens das escalas foram lidos para cada criança, sendo dado um cartão contendo as cinco opções de resposta (que variou de 'nunca' a 'sempre') para a criança apontar a freqüência aproximada da ocorrência de cada tipo de interação ou de acompanhamento. Essa aplicação foi feita de forma individual, em uma sala disponibilizada pela instituição, livre de interferências.

\section{Procedimento de análise dos dados}

Os dados provenientes do TDE foram pontuados com base no manual do instrumento. Com os dados quantitativos, provenientes do Questionário da Qualidade da Interação Familiar na Visão dos Filhos, análises descritivas (medidas de tendência central e dispersão) foram realizadas. Além disso, para os conjuntos de itens que compõem cada escala, foi feita uma análise de consistência interna da escala como um todo (calculando o alfa de Cronbach).

Para comparar os dois grupos de crianças (pais juntos e mães separadas) em relação ao envolvimento das mães com os filhos e ao desempenho acadêmico das crianças, utilizou-se o Teste-t. Para correlacionar a freqüência de envolvimento materno com o desempenho acadêmico das crianças, o teste de correlação linear de Pearson foi utilizado. Todas as análises quantitativas foram realizadas, usando o aplicativo SPSS 10.0 .

\section{Resultados}

Os resultados comparam e relacionam a freqüência da interação entre mãe e filho e o desempenho acadêmico das crianças, entre crianças que viviam com ambos os pais e crianças, com as mães, sendo apresentados em três conjuntos: interação entre mãe e filho; desempenho acadêmico das crianças e relações entre a interação mãe e filho e o desempenho acadêmico das crianças.

\section{Interação entre mãe e filho}

A Tabela I apresenta a freqüência de interações iniciadas pelas mães, para com seu filho, segundo a opinião dos filhos, comparando crianças que viviam com ambos os pais e crianças que viviam com as mães.

De modo geral, as mães de ambos os grupos mostraram alta freqüência de interação com os filhos. As duas diferenças encontradas, segundo a opinião das crianças, foram as seguintes: no grupo em que os pais moravam juntos, as mães perguntavam onde os filhos estavam indo e com quem, quando saíam de casa, com uma freqüência significativamente maior do que 
as mães monoparentais. Além disso, segundo as crianças, as mães monoparentais gritavam, xingavam ou
De novo, a maior parte dos itens não apresentou diferença estatisticamente significativa, entre os

Tabela I. Interação entre mãe e filho: Comparação de crianças que viviam com ambos os pais e crianças de mães monoparentais

\begin{tabular}{|c|c|c|c|c|c|c|}
\hline \multirow{2}{*}{$\begin{array}{l}\text { Item } \\
\text { Sua mãe... }\end{array}$} & \multicolumn{2}{|c|}{ Pais juntos } & \multicolumn{2}{|c|}{ Mães monoparentais } & \multicolumn{2}{|c|}{ Teste- $t$} \\
\hline & Média & D. P. & Média & D. P. & $\mathrm{t}$ & g1 \\
\hline $\begin{array}{l}\text { Quando você quer sair de casa, sua mãe pergunta } \\
\text { aonde você quer ir e com quem? }\end{array}$ & 4,87 & 0,35 & 4,20 & 1,14 & $2,15 *$ & 28 \\
\hline $\begin{array}{l}\text { Explica porque não pode fazer certas coisas (ex. } \\
\text { porque são perigosas, fazem mal para a saúde, } \\
\text { magoam outras pessoas)? }\end{array}$ & 4,80 & 0,56 & 4,33 & 1,18 & & \\
\hline Te ajuda quando você pede? & 4,67 & 0,49 & 4,47 & 1,19 & & \\
\hline $\begin{array}{l}\text { Fala para você não fazer certas coisas (impõe } \\
\text { limites a você)? }\end{array}$ & 4,60 & 0,83 & 4,80 & 0,78 & & \\
\hline Quando promete algo a você, faz o que prometeu? & 4,53 & 1,06 & 4,27 & 1,28 & & \\
\hline $\begin{array}{l}\text { Quando você fala com sua mãe, ela presta atenção } \\
\text { em você? }\end{array}$ & 4,27 & 1,10 & 4,07 & 1,23 & & \\
\hline $\begin{array}{l}\text { Fala para você quando gostou de algo que você } \\
\text { fez ou disse (elogia)? }\end{array}$ & 4,20 & 0,68 & 3,93 & 1,10 & & \\
\hline Dá carinho a você (abraça, beija)? & 3,93 & 1,16 & 4,00 & 1,56 & & \\
\hline $\begin{array}{l}\text { Conta coisas para você ou fala com você sem você } \\
\text { ter que fazer perguntas para ela? }\end{array}$ & 3,80 & 1,21 & 3,26 & 1,03 & & \\
\hline Pergunta para você sobre como foi seu dia? & 3,80 & 1,26 & 3,67 & 1,68 & & \\
\hline $\begin{array}{l}\text { Fala para você quando não gostou de algo que } \\
\text { você fez ou disse? }\end{array}$ & 3,73 & 1,28 & 3,53 & 1,13 & & \\
\hline $\begin{array}{l}\text { Pergunta para você sobre o que aconteceu na } \\
\text { escola? }\end{array}$ & 3,73 & 1,44 & 3,20 & 1,61 & & \\
\hline Grita com você quando você faz algo errado? & 3,33 & 1,59 & 3,87 & 1,51 & & \\
\hline Pergunta para você sobre seus amigos? & 3,07 & 1,03 & 2,47 & 1,36 & & \\
\hline Bate em você quando você faz algo de errado? & 2,53 & 1,19 & 3,20 & 1,57 & & \\
\hline $\begin{array}{l}\text { Grita, xinga ou bate em você sem que você tenha } \\
\text { feito algo errado (ex. porque está nervosa)? }\end{array}$ & 1,07 & 0,26 & 1,73 & 1,10 & $2,29 *$ & 28 \\
\hline Total & 3,81 & 0,37 & 3,67 & 0,77 & & \\
\hline
\end{tabular}

Nota: A freqüência foi apontada usando uma escala que variou de I, 'nunca' a 5 , 'sempre'.

${ }^{*} p<0,05$.

batiam nas crianças, sem que tenham feito algo de errado, com uma freqüência significativamente maior que as mães que eram casadas.

A Tabela 2 apresenta a freqüência de interações iniciadas pelos filhos, para com sua mãe, segundo a opinião dos filhos, comparando crianças que viviam com ambos os pais e crianças de mães separadas. dois grupos de crianças. Os dois itens envolvendo diferenças entre os dois grupos foram os seguintes: as crianças cujos pais moravam juntos apontaram que elas (as crianças) respondiam às perguntas que a mãe fazia, sem mentir ou esconder as coisas, com uma freqüência significativamente maior do que as crianças cujas mães eram separadas e as crian- 
Tabela 2. Interação entre filho e mãe: Comparação de crianças que viviam com ambos os pais e crianças de mães monoparentais

\begin{tabular}{|c|c|c|c|c|c|c|}
\hline \multirow{2}{*}{$\begin{array}{l}\text { Item } \\
\text { Você... }\end{array}$} & \multicolumn{2}{|c|}{ Pais juntos } & \multicolumn{2}{|c|}{ Mães monoparentais } & \multicolumn{2}{|c|}{ Teste- $t$} \\
\hline & Média & D. P. & Média & D. P. & $\mathrm{t}$ & $\mathrm{gl}$ \\
\hline Agradece quando sua mãe faz algo para você? & 4,60 & 0,74 & 4,13 & 1,30 & & \\
\hline $\begin{array}{l}\text { Fala para sua mãe quando gostou de algo que ela } \\
\text { fez ou disse (ex. fala para ela que ela está bonita, } \\
\text { que a comida esta gostosa)? }\end{array}$ & 4,33 & 0,82 & 4,53 & 0,83 & & \\
\hline $\begin{array}{l}\text { Conta para sua mãe sobre o que aconteceu na } \\
\text { escola? }\end{array}$ & 3,93 & 1,22 & 3,67 & 1,23 & & \\
\hline $\begin{array}{l}\text { Conta para sua mãe sobre seus amigos (conversas, } \\
\text { brincadeiras)? }\end{array}$ & 3,80 & 1,21 & 3,20 & 1,32 & & \\
\hline Conta para sua mãe sobre como foi seu dia? & 3,80 & 1,15 & 3,47 & 1,41 & & \\
\hline $\begin{array}{l}\text { Conta coisas para sua mãe ou fala com ela sem } \\
\text { que ela tenha que te fazer perguntas? }\end{array}$ & 3,67 & 1,40 & 3,53 & 1,51 & & \\
\hline Pede que sua mãe faça algo por você? & 3,67 & 0,98 & 4,13 & 1,30 & & \\
\hline $\begin{array}{l}\text { Responde às perguntas que sua mãe te faz sem } \\
\text { mentir ou esconder coisas? }\end{array}$ & 3,60 & 0,74 & 2,80 & 1,01 & $2,47 *$ & 25,56 \\
\hline Dá carinho a sua mãe (beija, abraça)? & 3,53 & 1,41 & 3,60 & 1,64 & & \\
\hline $\begin{array}{l}\text { Explica para sua mãe porque não quer fazer algo } \\
\text { do jeito que ela está te pedindo (ex. não te agrada; } \\
\text { é muito difícil para você)? }\end{array}$ & 3,47 & 0,92 & 3,07 & 1,33 & & \\
\hline $\begin{array}{l}\text { Pede que sua mãe o ajude a fazer atividades } \\
\text { escolares (tarefa de casa)? }\end{array}$ & 2,93 & 1,71 & 4,00 & 1,13 & $2,01 *$ & 28 \\
\hline $\begin{array}{l}\text { Fala para sua mãe quando não gostou de algo que } \\
\text { ela fez ou disse? }\end{array}$ & 2,87 & 1,46 & 2,93 & 1,16 & & \\
\hline $\begin{array}{l}\text { Tem dificuldade de contar seus problemas para } \\
\text { sua mãe? }\end{array}$ & 2,73 & 1,33 & 3,60 & 1,24 & & \\
\hline Desafia as regras de sua mãe (desobedece)? & 2,33 & 0,98 & 2,20 & 0,86 & & \\
\hline Grita com ou xinga sua mãe? & 1,27 & 0,59 & 1,47 & 0,99 & & \\
\hline Total & 3,37 & 0,48 & 3,36 & 0,53 & & \\
\hline
\end{tabular}

Nota: A freqüência foi apontada usando uma escala que variou de I, 'nunca' a 5 , 'sempre'. * $p<0,05$.

ças cujos pais eram separados apontaram que elas (as crianças) pediam que a mãe ajudasse a fazer atividades escolares, com uma freqüência significativamente maior do que as crianças cujas mães eram separadas.

A Tabela 3 apresenta a freqüência de participação das mães nas atividades escolares, culturais e de lazer dos filhos, segundo a opinião dos filhos, comparando crianças que viviam com ambos os pais e crianças com mães monoparentais.
Todas as mães mostraram um bom envolvimento em relação às atividades escolares, culturais e de lazer dos filhos, segundo o relato das crianças. No entanto, as crianças que moravam com ambos os pais apontaram que suas mães realizavam as seguintes atividades com uma freqüência significativamente maior do que as crianças com mães monoparentais: Pede que você faça tarefas domésticas; Procura te ajudar quando você tira notas ruins; Olha seus cadernos para ver se você tem tarefa de casa e Compra ou pega emprestado livros, gibis, revistas para você ler. 
Tabela 3. Participação das mães nas atividades escolares, culturais e de lazer dos filhos: Comparação de crianças que viviam com ambos os pais e crianças de mães monoparentais

\begin{tabular}{|c|c|c|c|c|c|c|}
\hline \multirow{2}{*}{$\begin{array}{l}\text { Item } \\
\text { Sua mãe... }\end{array}$} & \multicolumn{2}{|c|}{ Pais juntos } & \multicolumn{2}{|c|}{$\begin{array}{c}\text { Mães } \\
\text { monoparentais }\end{array}$} & \multicolumn{2}{|c|}{ Teste- $t$} \\
\hline & Média & D. P. & Média & D. P. & $\mathrm{t}$ & $\mathrm{gl}$ \\
\hline Fica feliz quando você tira notas boas (vai bem na escola)? & 4,60 & 0,74 & 4,47 & 1,19 & & \\
\hline Vai às reuniões de pais e mestres, na escola? & 4,53 & 0,74 & 3,93 & 1,58 & & \\
\hline $\begin{array}{l}\text { Pede para você guardar ou arrumar suas coisas (roupas, sapatos, } \\
\text { brinquedos)? }\end{array}$ & 4,47 & 0,74 & 4,67 & 1,05 & & \\
\hline $\begin{array}{l}\text { Te dá algo bom ou te diz algo bom quando você tira notas boas } \\
\text { (vai bem na escola)? }\end{array}$ & 4,40 & 0,99 & 3,93 & 1,28 & & \\
\hline $\begin{array}{l}\text { Ajuda ou lembra você de fazer atividades de higiene (escovar } \\
\text { dentes, tomar banho)? }\end{array}$ & 4,40 & 0,83 & 4,47 & 1,24 & & \\
\hline Almoça ou janta junto com você? & 4,40 & 0,83 & 3,87 & 1,60 & & \\
\hline $\begin{array}{l}\text { Pede que você faça tarefas domésticas (arrumar sua cama, lavar } \\
\text { louça, varrer a casa)? }\end{array}$ & 4,27 & 1,16 & 3,33 & 1,54 & $1,87+$ & 28 \\
\hline Te ajuda com as lições de casa quando você precisa? & 4,00 & 1,31 & 3,73 & 1,49 & & \\
\hline Procura te ajudar quando você tira notas ruins (vai mal na escola)? & 4,00 & 1,19 & 2,87 & 1,77 & $2,05 *$ & 28 \\
\hline Pede a você para ler livros, gibis, revistas? & 3,93 & 1,53 & 3,27 & 1,71 & & \\
\hline Olha seus cadernos para ver se você tem tarefa de casa? & 3,87 & 1,30 & 2,80 & 1,78 & $1,87+$ & 28 \\
\hline Olha seus cadernos para ver se você fez a tarefa de casa? & 3,73 & 1,44 & 3,33 & 1,79 & & \\
\hline Pede que você tente fazer a lição de casa sozinho? & 3,54 & 1,67 & 3,07 & 1,75 & & \\
\hline Deixa seus colegas virem brincar na sua casa? & 3,53 & 1,30 & 3,40 & 1,59 & & \\
\hline $\begin{array}{l}\text { Fica brava (dá bronca) quando você tira notas ruins (vai mal na } \\
\text { escola)? }\end{array}$ & 3,47 & 1,41 & 3,53 & 1,41 & & \\
\hline Compra brinquedos para você (aniversário, natal)? & 3,33 & 1,54 & 3,40 & 1,59 & & \\
\hline Deixa você brincar na casa de seus colegas? & 3,33 & 1,49 & 3,67 & 1,54 & & \\
\hline Recebe visitas de amigos de seus pais na sua casa? & 3,33 & 1,40 & 2,87 & 1,12 & & \\
\hline Assiste filmes/desenhos com você em casa? & 3,30 & 1,29 & 4,07 & 1,53 & & \\
\hline Recebe pessoas da família em sua casa (visita)? & 3,30 & 0,94 & 3,27 & 1,22 & & \\
\hline Freqüenta uma igreja (algo similar)? & 3,07 & 1,44 & 3,27 & 1,16 & & \\
\hline Sai de casa com você para visitar pessoas da família? & 3,07 & 1,39 & 3,13 & 1,25 & & \\
\hline Brinca com você? & 3,00 & 1,69 & 2,20 & 1,14 & & \\
\hline Passeia com você (clube, shopping, zoológico, circo, parque)? & 2,80 & 1,32 & 3,33 & 2,67 & & \\
\hline $\begin{array}{l}\text { Leva você para fazer alguma atividade esportiva (jogar futebol, } \\
\text { nadar, brincar num parque)? }\end{array}$ & 2,73 & 1,33 & 2,07 & 1,17 & & \\
\hline Sai de casa para visitar amigos? & 2,53 & 1,19 & 2,00 & 1,00 & & \\
\hline Compra ou pega emprestado livros, gibis, revistas para você ler? & 2,47 & 1,41 & 1,20 & 0,56 & $3,24 * *$ & 28 \\
\hline Ajuda você a se vestir (escolher roupas, amarrar cadarços)? & 2,47 & 1,41 & 2,33 & 1,54 & & \\
\hline Coloca comida no seu prato? & 2,33 & 1,76 & 3,20 & 1,74 & & \\
\hline Leva você na casa de seus colegas para brincar? & 2,33 & 1,40 & 2,13 & 1,30 & & \\
\hline Lê, conta histórias para você? & 2,00 & 1,19 & 1,60 & 0,99 & & \\
\hline Leva você ao cinema ou teatro infantil ou shows musicais? & 1,47 & 0,51 & 1,73 & 0,79 & & \\
\hline Total & 3,41 & 0,52 & 3,13 & 0,61 & & \\
\hline
\end{tabular}

Nota: A freqüência foi apontada usando uma escala que variou de I, 'nunca' a 5 , 'sempre'. $+p<0, \mathrm{I} ;$ * $p<0,05$; ** $p<0,0$ I. 


\section{Desempenho acadêmico das crianças}

A Tabela 4 apresenta as médias das crianças nos subtestes do TDE.

Não houve diferenças estatisticamente significativas no desempenho acadêmico, entre as crianças que série para ter uma distribuição equivalente à das crianças da $3^{\mathrm{a}}$ série. Para tanto, foram retirados quatro pontos dos escores de cada criança da $4^{a}$ série em aritmética, três pontos em escrita e sete pontos da pontuação total no TDE.

Tabela 4. Pontuação obtida no Teste de Desempenho Escolar por série

\begin{tabular}{|c|c|c|c|c|}
\hline \multirow{2}{*}{ TDE } & \multicolumn{2}{|c|}{$3^{a}$ série } & \multicolumn{2}{|c|}{$4^{\mathrm{a}}$ série } \\
\hline & Média & D. P. & Média & D. P. \\
\hline Aritmética & 15,7 & 3,53 & 17,4 & 4,38 \\
\hline Escrita & 24,2 & 6,73 & 27,3 & 5,85 \\
\hline Leitura & 62,3 & 11,18 & 62,7 & 16,84 \\
\hline Pontuação total & 102,2 & 18,95 & 107,4 & 17,16 \\
\hline
\end{tabular}

viviam com ambos os pais e as crianças vivendo com mães monoparentais. Por isso, optou-se por apresentar as médias das crianças da $3^{\mathrm{a}}$ e $4^{\mathrm{a}}$ séries, sem separá-las pelas constituições familiares.

Em aritmética, as crianças da $3^{\mathrm{a}}$ série estavam na média e as da $4^{\text {a }}$ série estavam ligeiramente abaixo da média, de acordo com as normas de classificação do TDE. No subteste de escrita, as crianças de ambas as séries estavam na média e, no subteste de leitura, ambas estavam abaixo da média. No escore total, as crianças da $3^{\mathrm{a}}$ série estavam na média e as da $4^{\mathrm{a}}$ série estavam abaixo da média.

\section{Relações entre a interação mãe e filho e o desempenho acadêmico das crianças}

Para correlacionar as três medidas do envolvimento mãe-filho com o desempenho acadêmico das crianças, foi necessário combinar os escores das crianças da $3^{\mathrm{a}}$ e $4^{\mathrm{a}}$ séries no TDE. Sempre que é preciso combinar dados de dois grupos independentes, com distribuições normais, mas médias diferentes pode-se subtrair ou somar um valor fixo a todos os escores de um dos grupos, para transpor a média para o mesmo valor do segundo grupo, sem afetar a forma da distribuição dos escores do primeiro grupo (Hays, 198I). Sendo assim, optouse por transformar os escores das crianças da $4^{a}$
A Tabela 5 mostra as correlações entre as medidas de interações mãe-filho e o desempenho acadêmico das crianças, considerando as crianças que moravam com ambos os pais.

Pode-se verificar que houve uma correlação positiva e significativa entre a pontuação total no TDE e os dois itens das escalas de envolvimento materno: a freqüência de a mãe gritar com o filho, quando faz algo errado, e a frequiência da criança falar para sua mãe quando não gostou de algo que ela fez ou disse.

A Tabela 6 mostra as correlações entre as medidas de interação mãe-filho e o desempenho acadêmico das crianças, considerando as crianças que moram apenas com a mãe.

Pode-se verificar que algumas habilidades comunicativas e várias atividades que as mães estavam realizando com os filhos estavam correlacionadas com pelo menos um dos subtestes do TDE. Ou seja, percebe-se que o envolvimento materno no contexto monoparental estava altamente relacionado com o desempenho acadêmico dos seus filhos.

Em relação ao primeiro conjunto de dados - envolvendo a comparação do grupo de crianças com mães monoparentais com o de crianças cujos pais viviam juntos, em relação à freqüência de cada tipo de interação mãe-filho, de modo geral, segundo relato das crianças, houve alta freqüência de interação das 
Tabela 5. Correlações significativas (Pearson) entre os indicadores de envolvimento materno e o desempenho escolar de crianças cujos pais moravam juntos

\begin{tabular}{|c|c|c|c|c|}
\hline \multirow{2}{*}{\multicolumn{2}{|c|}{ Tipo de envolvimento materno }} & \multicolumn{3}{|c|}{ TDE } \\
\hline & & \multirow[t]{2}{*}{ Leitura } & \multirow[t]{2}{*}{ Escrita } & \multirow{2}{*}{$\frac{\text { Total }}{0,539 *}$} \\
\hline Interação mãe e fillho & Grita com você quando você faz algo errado? & & & \\
\hline \multirow[b]{2}{*}{ Interação filho e mãe } & $\begin{array}{l}\text { Fala para sua mãe quando não gostou de algo } \\
\text { que ela fez ou disse? }\end{array}$ & & & $0,518^{*}$ \\
\hline & $\begin{array}{l}\text { Explica para sua mãe porque não quer fazer } \\
\text { algo do jeito que ela está te pedindo (ex. não te } \\
\text { agrada; é muito difícil para você)? }\end{array}$ & $0,535^{*}$ & & \\
\hline
\end{tabular}

Participação das mães nas

atividades escolares,

culturais e de lazer dos

Deixa seus colegas virem brincar na sua casa? $\quad 0,545^{*} \quad 0,520^{*}$

filhos

Nota: $* p<0,05$.

Tabela 6. Correlações significativas (Pearson) entre os indicadores de envolvimento materno e o desempenho escolar de crianças com mães monoparentais

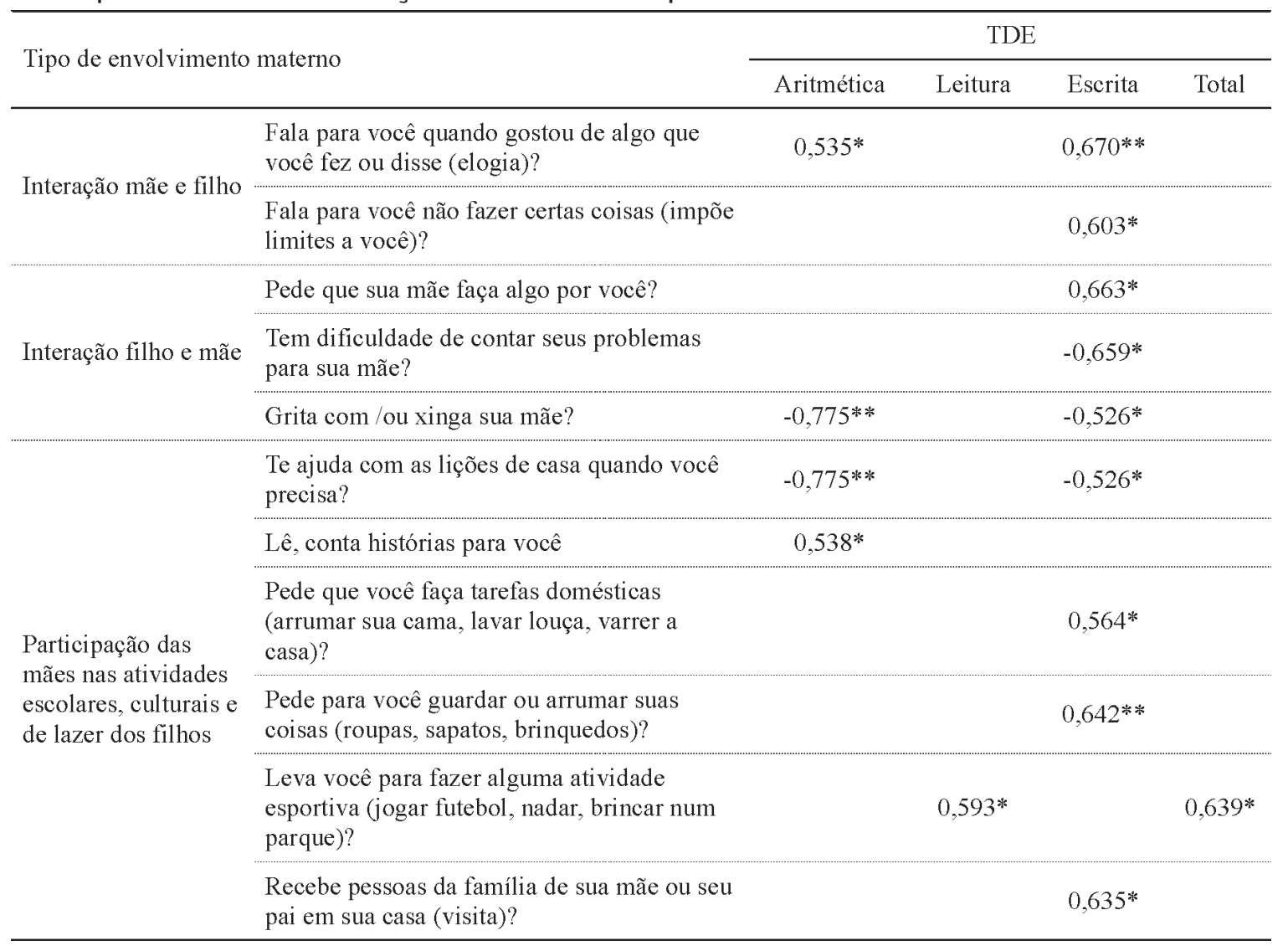

Nota: $* p<0,05 ; * * p<0,01 ; * * * *<<0,001$.

mães com os filhos em ambos grupos de crianças. De acordo com a literatura (Alvarenga \& Piccinini, 200I; Anselmi, Piccinini, Barros \& Lopes, 2004; Atzaba-Poria, Pike \& Deater-Deckard, 2004;
D’Affonseca, 2005; D’Avila-Bacarji, Maturano \& Elias, 2005; Hill \& Taylor, 2004; Kenny \& Gallagher, 2002), o bom envolvimento de um adulto responsável contribui para a maximização de diversas áreas do de- 
senvolvimento infantil, especialmente o desenvolvimento sócio-emocional e cognitivo.

Entretanto, foi possível observar algumas diferenças na interação das mães bi e monoparentais com seus filhos. Parece que as mães no contexto bi-parental dispunham de mais tempo, em média, do que as mães monoparentais, para monitorar as atividades sociais de seus filhos (Kauffman, 200I; Tiedje, 2004).

Além disso, as mães monoparentais apresentaram maior freqüência de alguns comportamentos negativos, o que também pode ser um indício de que estas mães estejam mais estressadas do que as mães do contexto biparental. Como as mães monoparentais costumam lidar com um acúmulo maior de funções do que mães agindo num contexto bi-parental, isto pode gerar maior estresse e cansaço, associados a maior nervosismo e menor paciência para com os filhos.

Observou-se também que as crianças com mães monoparentais apontaram que mentem ou escondem coisas de suas mães com uma freqüência significativamente maior do que as crianças cujos pais viviam juntos. Mentir e esconder coisas tende a acontecer quando a reação esperada por parte da mãe seria punitiva. A falta de transparência e interações negativas interferem na qualidade do envolvimento materno e, por conseqüência, torna-se um fator de risco para o desenvolvimento infantil (Coley, 200I; Tubbs, Roy \& Burton, 2005).

Considerando a participação das mães nas atividades escolares, culturais e de lazer dos filhos, pode-se notar que as crianças que moravam com ambos os pais apontaram contar com um envolvimento materno mais freqüente do que no grupo de crianças com mães monoparentais em relação a diversos itens. As mães, que contam com a presença do marido, podem ter mais tempo disponível para ajudar e monitorar as atividades escolares dos filhos e ainda terem melhor condição financeira para comprar coisas para seu filho (Guille, 2004).

Com relação ao segundo objetivo, visando à comparação do desempenho acadêmico das crianças que moravam com ambos os pais e das crianças que viviam somente com a mãe, não houve diferenças significativas. Porém, todas as crianças tiveram um desempenho acadêmico abaixo da média em vários subtestes do TDE, considerando que o desempenho acadêmico pode ser influenciado por um conjunto de variáveis, além do envolvimento materno. O impacto negativo de tais variáveis se torna mais evidente, considerando que as crianças estavam tendo reforço escolar e, ainda assim, apresentaram um desempenho acadêmico abaixo do esperado (D'Affonseca, 2005; Del Prette \& Del Prette, 2005; Marturano, 2004).

Em relação ao terceiro objetivo, que relacionou a interação entre mãe e filho e o desempenho acadêmico das crianças, os resultados mostraram a ocorrência de algumas correlações significativas em ambos os grupos de crianças. No entanto, para o grupo de crianças que viviam somente com a mãe, houve um número muito maior de itens correlacionados com o desempenho acadêmico das mesmas do que no outro grupo de mães. Como não há a presença do pai no grupo monoparental, o que a mãe fazia não estava sendo complementado por uma outra pessoa. Assim, parece que suas ações tiveram um impacto direto sobre o filho.

No contexto bi-parental, porém, o pai pode reforçar ou modificar o impacto do que a mãe faz. Assim, no contexto bi-parental, se fosse considerar o envolvimento da mãe e do pai, em conjunto, pode ser que passar-se-ia a ter muito mais correlações entre o envolvimento dos pais e o desempenho acadêmico de crianças.

Para o grupo de crianças que viviam apenas com a mãe, os comportamentos da mãe de elogiar, impor limites e solicitar que os filhos ajudem em tarefas domésticas foram os itens mais fortemente associados com o desempenho acadêmico dos filhos. A literatura também indica que o reforço positivo aos comportamentos dos filhos, a imposição de regras e limites e a divisão de responsabilidades com os filhos contribuem para maximizar o desenvolvimento psicossocial e intelectual das crianças, ajudando-as no seu desempenho escolar (Cooper \& Cooper, 2005; Del Prette \& Del Prette, 2005).

É importante salientar que, no contexto monoparental, houve uma correlação significativa e negativa entre a ajuda com tarefas escolares por parte da mãe, por um lado, e o desempenho acadêmico das crianças em aritmética e em escrita, por outro lado. Esse dado está em acordo com Tiba (2006), 
que afirma que muitas mães crêem que quando executam as tarefas escolares para as crianças (no lugar delas), estão ajudando, mas apenas contribuem para interferir na aprendizagem das mesmas.

Considerando o conjunto de correlações entre envolvimento materno e desempenho acadêmico das crianças que surgiram nos dois grupos, percebe-se que nenhum foi muito alto. Além disso, embora aparecerem várias correlações significativas, um número muito maior dos itens das escalas de envolvimento materno não apresentaram correlações significativas com o desempenho escolar.

Domina (2005) afirma que o envolvimento parental, como também sua eficácia, tende a declinar com o aumento da idade da criança. Assim, como a faixa etária pesquisada variou entre nove e onze anos, pode-se supor que muitas das crianças já tenham adquirido alto nível de independência com relação às atividades ligadas ao seu desempenho acadêmico, com nível apenas mediano de necessidade de apoio por parte de suas mães, reduzindo a probabilidade de detectar correlações significativas.

\section{Considerações Finais}

Ainda que este estudo tenha sido conduzido com uma amostra restrita de participantes, os resultados claramente confirmam vários outros achados na literatura, referentes à importância do envolvimento materno para o desempenho acadêmico de escolares, assim como aponta para algumas diferenças na freqüência e tipo de envolvimento materno entre mães bi e monoparentais. Assim, com base neste estudo, parece que seria frutífero prosseguir com pesquisas em amostras ampliadas, considerando diferentes estratos sociais.

Deve-se ressaltar, também, que alguns dos resultados deste estudo são correlacionais. Portanto, conclusões sobre a direção causal da relação entre envolvimento materno e desempenho escolar não podem ser estabelecidas. Estudos longitudinais seriam indicados para monitorar melhor a influência do envolvimento materno sobre o desempenho acadêmico, ao longo do período de escolarização.
A maior freqüência de alguns comportamentos negativos no grupo de mães monoparentais, segundo seus filhos, é preocupante, porque parece refletir uma situação de maior sobrecarga e estresse no contexto mono do que no contexto biparental. Dessa forma, estes resultados podem ajudar a fundamentar e direcionar intervenções para famílias monoparentais, enfocando sua necessidade de apoio prático e emocional e trabalhando com os comportamentos específicos que apresentaram correlações negativas com o desempenho acadêmico das crianças.

Uma contribuição metodológica importante a ressaltar em relação a este estudo foi o uso de relatos das crianças. $\mathrm{Na}$ maioria dos estudos, quando se procura coletar dados sobre a relação mãe-fiIho, o ponto de vista mais procurado seria o da mãe, supondo que ela seria uma informante mais fidedigna. Porém, a opinião da criança sobre o envolvimento de sua mãe é muito importante para verificar a relação entre este e o desempenho escolar da criança. Em suma, acredita-se que este estudo permite saber mais sobre as semelhanças e diferenças no envolvimento materno nos contextos bi e monoparentais, bem como a relação entre este envolvimento e o desempenho escolar de seus filhos. Tendo em vista o aumento na porcentagem de crianças vivendo no contexto monoparental, é de extrema importância ter informações detalhadas comparando estes dois contextos a fim de compreender as necessidades específicas de cada tipo de família e oferecer apoios adaptados a cada contexto.

\section{Referências}

Alvarenga, P., \& Piccinini, C. (200I). Práticas educativas maternas e problemas de comportamento em pré-escolares. Psicologia: Reflexão e Crítica, 14(3), 449-460.

Anselmi, L., Piccinini, C. A., Barros, F. C., \& Lopes, R. S. (2004). Psychosocial determinants of behavior problems in Brazilian preschool children. Journal of Child Psychology and Psychiatry, 45(4), 779-788. 
Appleyard, K., Egeland, B., Dulmen, M. H. M. V., \& Sroufe, L. A. (2005). When more is not better: The role of cumulative risk in child behavior outcomes. Journal of Child Psychology and Psychiatry, 46(3), 235-245.

Atzaba-Poria, N., Pike, A., \& Deater-Deckard, K. (2004). Do risk factors for problem behavior act in a cumulative manner? An examination of ethnic minority and majority children through an ecological perspective. Journal of Child Psychology and Psychiatry, 45, 707-7I8.

Branvdth, B., \& Kvande, E. (2002). Reflexive fathers: Negotiating parental leave and working life. Gender, Work and Organization, 9(2), I86-203.

Cia, F., D’Affonseca, S. M., \& Barham, E. J. (2004). A relação entre envolvimento paterno e desempenho acadêmico dos filhos. Paidéia: Cadernos de Psicologia e Educação, 14(29), 277286.

Coley, R. L. (200I). (In)visible Men - Emerging research on low-income, unmarried, and minority fathers. American Psychologist, 56(9), 743-753.

Cooper, B., \& Cooper, N. (2005). What a difference a parent makes! New York: A focus on father workbook.

D’Affonseca, S. M. (2005). Prevenindo fracasso escolar: Comparando o autoconceito e desempenho acadêmico de filhos de mães que trabalham fora e donas de casa. Dissertação de Mestrado não-Publicada, Programa de Pós-graduação em Educação Especial, Universidade Federal de São Carlos, São Carlos, São Paulo.

D’Avila-Bacarji, K. M. G., Marturano, E. M., \& Elias, L. C. S. (2005). Suporte parental: Um estudo sobre crianças com queixas escolares. Psicologia em Estudo, I0(I), I07-II 5.

Dantas, C., Jablonski, B., \& Féres-Carneiro, T. (2004). Paternidade: Considerações sobre a relação pais-filhos após a separação conjugal. Cadernos de Psicologia e Educação Paidéia, 14(29), 347-357.

Del Prette, Z. A. P., \& Del Prette, A. (2005). Psicologia das habilidades sociais na infância: Teoria e Prática. Petrópolis: Vozes.

Dessen, M. A., \& Silva, N. L. P. (2004). A família e os programas de intervenção: Tendências atuais. Em E. G. Mendes, M. A. Almeida \& L. C. A. Williams (Orgs.), Avanços recentes em Educação Especial (pp. I79-187). São Carlos: EDUFSCar.

Domina, T. (2005). Leveling at home advantage: Assessing the effectiveness of parental involvement in elementary school. Sociology of Education, 78, 233-249.
Dunn, J. (2004). Annotation: Children's relationships with their nonresident father. Journal of Child Psychology and Psychiatry, 45(4), 659-67I.

Ferreira, V. (2005). Família: Nó ou ninho? [On-line]. Disponível: www.vidaacademica.net.

Flouri, E., \& Buchanan, A. (2003). The role of father involvement in children's later mental health. Journal of Adolescence, 26, 63-78.

Guille, L. (2004). Men who batter and their children: An integrated review. Aggression and Violent Behavior, 9, I29-163.

Gutman, L. M., Sameroff, A. J., \& Cole, R. (2003). Academic growth curve trajectories from Ist grade to 12 th grade: Effects of multiple social risk factors and preschool child factors. Developmental Psychology, 39(4), 777-790.

Hays, W. L. (198I). Statistics. Toronto, ON: Holt Reinharte Winston.

Hill, N. E., \& Taylor, L. C. (2004). Parental school involvement and children's academic achievement. Current Directions in Psychological Science, 13(4), I6I-I64.

Jaffee, S. R., Moffitt, T. E., Caspi, A., \& Taylor, A. (2003). Life with (or without) father: The benefits of living with two biological parents depend on the father's antisocial behavior. Child Development, 74(I), 109-126.

Kauffman, J. M. (200I). Characteristics of emotional and behavioral disorders of children and youth. New Jersey, $\mathrm{OH}$ : Merril Prentice Hall.

Kenny, M. E., \& Gallagher, L. A. (2002). Instrumental and social/relational correlates of perceived maternal and paternal attachment in adolescence. Journal of Adolescence, 25, 203219.

Lamb, M. E. (1997). Fathers and child development: An introductory overview and guide. Em M. E. Lamb (Org.), The role of the father in child developmental (pp. I-18). New York: John Wiley \& Sons.

Marturano, E. M. (2004). Fatores de risco e proteção no desenvolvimento socioemocional de crianças com dificuldade de aprendizagem. Em E. G. Mendes, M. A. Almeida \& L. C. A. Williams (Orgs.), Temas em Educação Especial - Avanços Recentes (pp. I59-165). São Carlos: EDUFSCar.

Stein, L. M. (1994). Teste de desempenho escolar. São Paulo: Casa do Psicólogo.

Tiba, I. (2006). Disciplina na medida certa: Novos paradigmas. São Paulo: Integrare. 
Tiedje, L. B. (2004). Process of change in work/home incompatibilities employed mothers. Journal of Social Issues, 60(4), 787-800.

Tubbs, C. Y., Roy, K. M., \& Burton, L. M. (2005). Families ties: Constructing family time in low-income families. Family Process, 44(I), 77-9I.
Zigler, E. F., \& Finn-Stevenson, M. (1997). Policy efforts to enhance child and family life: Goals for 20 I0. Em R. P. Weissberg, T. P. Gullota, R.L. Hampton, B. A. Ryan \& G. R. Adams (Orgs.), Establishing preventive services (pp. 27-60). Thousand Oaks, CA: Sage.

Recebido em: 13/03/2007

Revisado em: 04/06/2007

Aprovado em: 31/01/2008

Sobre as autoras

Carolina Severino Lopes da Costa (carollina_costa@yahoo.com.br) - Psicóloga, Doutoranda pelo Programa de Pós-Graduação em Educação Especial da Universidade Federal de São Carlos.

Fabiana Cia (fabianacia@hotmail.com) - Psicóloga, Doutoranda pelo Programa de Pós-Graduação em Educação Especial da Universidade Federal de São Carlos.

Elizabeth Joan Barham (lisa@power.ufscar.br) - Professora do Departamento de Psicologia e do Programa de Pós-Graduação em Educação Especial da Universidade Federal de São Carlos.

Envio de correspondência/Leitor do artigo

Universidade Federal de São Carlos

Departamento de Psicologia/Laboratório de Análise e Prevenção de Violência (LAPREV)

A/C: Carolina Severino Lopes da Costa

Rodovia Washington Luís, Km 235, Caixa Postal: 676, CEP: 13565-905

São Carlos - SP - Brasil.

Telefones: (I6) 335I-8745 / (I6) 335I-836I

carollinacosta@yahoo.com.br

Nota das autoras

Apoio Financeiro: CAPES

Este trabalho foi originalmente desenvolvido como requisito da disciplina Estudos Avançados, do Programa de Pós-Graduação em Educação Especial/ UFSCar, ministrada pelas Profas. Dra. Deisy das Graças de Souza, Dra. Maria Stella Coutinho de Alcântara Gil e Dra. Cláudia Maria Simões Martinez. 